\title{
Experimental Study on Nonionic Surfactants for Minimizing Surface Adsorption as an Improved Oil Recovery (IOR) Process
}

\author{
M. J. A. Prince* \\ Department of Petroleum Engineering, Amet University, Chennai, India; \\ Prince466@gmail.com
}

\begin{abstract}
Adsorption of surfactants onto the surfaces during chemical flooding is a major problem in EOR and IOR process. This happens due to blockage of capillary pores and opposite charge on the surface. The objective of this paper is to reduce adsorption of anionic surfactants by application of no nonionic surfactants as an IOR process. The methodology for Selection of surfactants for core flooding has been done based on conductivity and emulsion tests. Nonionic surfactants Ethoxylated Alcohol (EO) of 1000ppm from emulsion test has been chosen to reduce adsorption of anionic surfactants Sodium Dodecyle Sulphate (SDS) of 750ppm determined from conductivity test. Core flooding experiment with anionic surfactants has been conducted with nonionic surfactants and without the influence of nonionic surfactants. Reduction in adsorption of anionic surfactants SDS up to 1.2 pore volume has been observed in the on core flooding experiment.
\end{abstract}

Keywords: Adsorption, EOR, IOR, Nonionic Surfactants

\section{Introduction}

The ability of surfactants to alter properties at interface and surface has economical applications in oil and gas industry mainly on Enhanced Oil Recovery (EOR) and Improved Oil Recovery (IOR) methods ${ }^{1}$.

Additional technologies with EOR as IOR attained lot of attention since last decade. Adsorption of surfactants onto the surface of reservoirs has noticed to be a great problem for chemical EOR methods ${ }^{2}$. Adsorption is mainly dependent on hydrophobicity and salinity. Designing surfactants with less adsorption is being a great challenge to petroleum industry. After waterflooding, unswept oil could not be recovered effectively by surfactants because of adsorption. As much adsorption on surface, makes less contact with oil. Nonionic surfactants have been tested successfully on Yates field as a stimulation technique ${ }^{3}$.

The forces which are influencing Surfactant adsorption at Interface is a combination of electrostatic, chemical, lateral chain-chain associative interaction, hydrogen bonding and de-solvation of adsorbate species. The surfactants at lower concentrations will be adsorbed on the basis of hydrophobic interactions between molecules $^{4}$. At a specific concentration, it reaches its optimum at the critical micelle concentration ${ }^{5}$.

Since, Nonionic surfactants has good potential in altering wettability, it was investigated to improve contact between anionic surfactants selected for IFT reducer between Oil and water. Nonionic surfactants at low concentrations will adsorb onto the surface and increases the $\mathrm{pH}$ and decreases the number of positive sites available for

*Author for correspondence 
the adsorption on the surface. Eventually the charge on the surface will become negative which reduces adsorption among anionic surfactants ${ }^{6}$.

Normally after water flooding in an Oil wet reservoir, residual oil will be left behind larger pores due to insufficient penetration and contact. This happens due to reservoirs Oil wetting nature blocking the larger pore by smaller pores. Nonionic surfactants are viscous and stable at any kind of wetting surfaces because they don't posses any charge. With these properties it can enhance permeability and contact by adsorbing itself to surface ${ }^{7}$.

\section{Methods}

\subsection{CMC Measurement by Conductivity} Test

Surfactants are stable when they form micelles at specific concentration. CMC is the addition of surfactant to an aqueous solution causes an increase in the number of charge carriers $\left(\mathrm{Na}^{+}\right.$(aq) and ${ }^{-} \mathrm{OSO}_{3} \mathrm{C}_{12} \mathrm{H}_{25}$ (aq) and consequently, increase in the conductivity. Above the $\mathrm{CMC}$, further addition of surfactant increases the micelle concentration while the monomer concentration remains approximately constant at the CMC level. Since a micelle is much larger than a SDS monomer it diffuses more slowly through solution and so is a less efficient charge carrier. A plot of conductivity against surfactant concentration is, thus expected to show a break at the $\mathrm{CMC}^{8}$.

\section{Observations and Results}

Crude oil was selected from an X field having viscosity $35 \mathrm{cp}$. Nonionic surfactants as ethoxylated alcohol (EO) of HLB 8.0 and viscosity $26 \mathrm{cp}$ at temperature $25^{\circ} \mathrm{C}$ for altering $\mathrm{pH}$ and Anionic surfactants as Sodium Dodecyl Sulphate (SDS) as IFT reducer. The concentrations for SDS and EO were selected based on emulsion studies.

Nine samples of surfactant concentrations were prepared. SDS from vendor was $36 \%$ active. $2.7 \mathrm{ml}$ from $100 \mathrm{ml}$ SDS as $1 \mathrm{wt} \%$ aqueous was dissolved in $100 \mathrm{ml}$ for $10,000 \mathrm{ppm}$. $100 \mathrm{ppm}$ as $1 \mathrm{ml}$ taken into conductivity cell with distilled water and electrode. Conductivities for every addition of 100ppm were calculated shown in Table 1. Conductivities have been plotted against concentrations for CMC measurement shown in Figure 1. Deviation has been observed at $750 \mathrm{ppm}$. The optimum concentration for CMC is 750ppm where the deviation has been observed.

\subsection{Emulsion Test}

For EO, Optimum Concentration for core flooding has been determined by emulsion tests. Five Emulsions

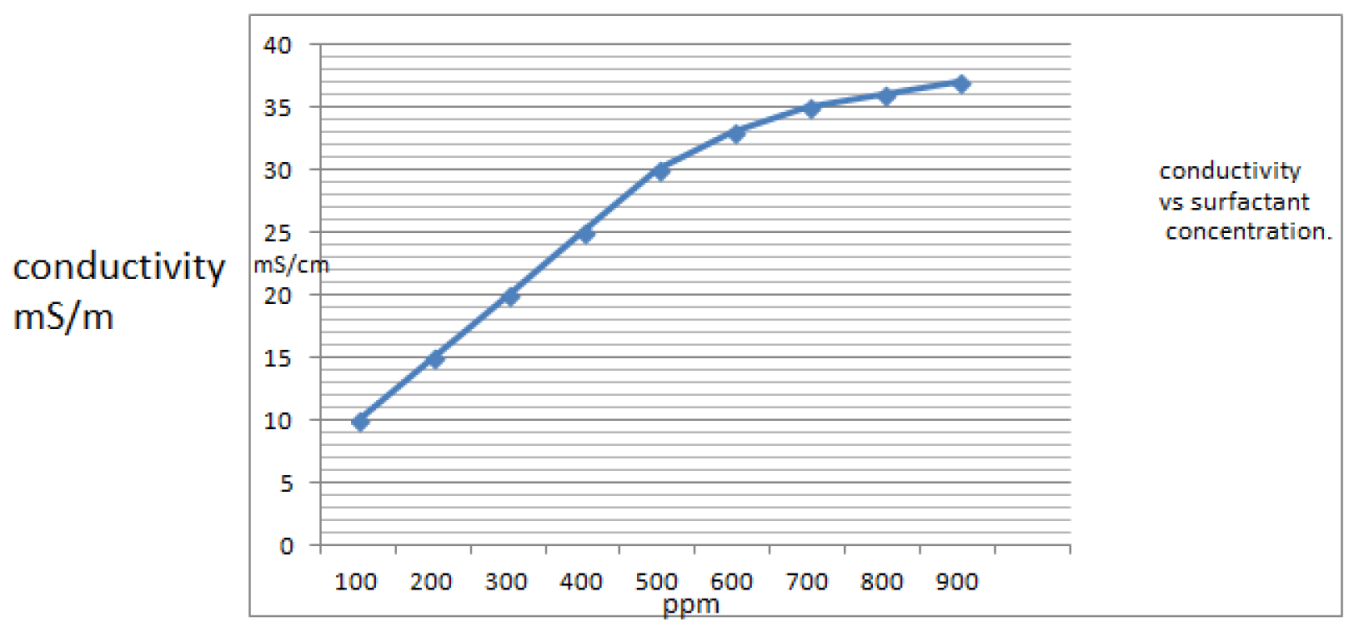

concentration

Figure 1. CMC determination. 
varying concentrations of surfactants with constant brine and Oil were prepared. Clear Middle layer at 1000ppm have been observed as shown in Table 2. 1000ppm of EO was chosen for core analysis.

\subsection{Core Analysis}

Core flooding operation has been conducted on 3 categories. In first, adsorption of SDS has been observed and in second how much EO has reduced the SDS adsorption. Third, recovery of oil by injecting both types of surfactants simultaneously.

Initially Berea Core $\left(3 \times 3 \mathrm{~cm}^{2}\right.$ Area $)$ was dried in a vacuum oven at $90^{\circ} \mathrm{C}$ for 24 hours. It has porosity of 0.23 , permeability of $55 \mathrm{md}$. They were then saturated under vacuum with degassed brine, oil flooded up to connate water saturation, and then water flooded to residual oil saturation usually in the range of 30 to $35 \%$ of Pore Volume $(\mathrm{PV})$. Pore volume $(\mathrm{PV})$ is determined by injecting water continuously into the core in a vacuum condition. How

Table 1. Conductivity measurements for surfactant concentration

\begin{tabular}{lcc}
\hline SAMPLE & $\begin{array}{c}\text { surf.conc } \\
\text { ppm }\end{array}$ & $\begin{array}{c}\text { conductivity } \\
\text { mS/cm }\end{array}$ \\
\hline 1 & 100 & 10 \\
2 & 200 & 15 \\
3 & 300 & 20 \\
4 & 400 & 25 \\
5 & 500 & 30 \\
6 & 600 & 33 \\
7 & 700 & 35 \\
8 & 800 & 36 \\
9 & 900 & 37 \\
\hline
\end{tabular}

Table 2. Emulsion Test for micro emulsion

\begin{tabular}{ccc}
\hline & EO \\
\hline ppm & Brine Wt \%. & Appearance \\
\hline 0 & 0.5 & 2 phases \\
500 & 0.5 & 2 phases \\
$1000 \mathrm{ppm}$ & 0.5 & 3 phases clear \\
2000 & 0.5 & 3 phases cloudy \\
3000 & 0.5 & 2 phases \\
\hline
\end{tabular}

much water it has been adsorbed will be considered as pore volume. Injection rate was kept constant throughout the experiment $(\mathrm{q}=5 \mathrm{ml} / \mathrm{h})$, the core was saturated with injection water TDS $(60 \mathrm{~g} / \mathrm{l})$.

$5 \mathrm{PV}$ of SDS (750ppm aqueous) have been injected into core followed by water $(60 \mathrm{~g} / \mathrm{L})$. Surfactants have observed at outlet after injecting 3.2 PV. The adsorption of SDS onto the core has been calculated as 2.2. Core was saturated by water and followed by $\mathrm{EO}$ of $5 \mathrm{PV}$ have been injected. With water $(60 \mathrm{~g} / \mathrm{l})$ injection surfactants were recovered. Then SDS was injected with $5 \mathrm{PV}$. Break through has observed to be 2.0 PV. Adsorption of SDS has observed to be $1.0 \mathrm{PV}$.

Finally, core was saturated by oil followed by water injection. After water injection, EO and SDS were injected simultaneously. Oil has been recovered as $38 \%$ with $1.5 \mathrm{PV}$ of SDS adsorption.

\section{Conclusion}

According to core flooding, adsorption of SDS has been reduced to 1.0 PV, from 2.2 PV. Still, 1.0 PV has adsorbed because of hydrophobic on surface and impurities ${ }^{9}$. With reducing adsorption, contact among surfactants and oil will improve. Eventually recovery will become maximum by reducing IFT $^{10}$.

Nonionic Surfactants have been found in numerous applications in oil fields. Their properties to alter surface characteristics, stability at high salinity and temperatures made them more attractive for research. They exhibit good viscoelastic property which has great scope in chemical EOR. They enhance permeability and blocks to improve contact with fluids. Research has to be conducted on limestone and dolomite reservoirs.

\section{References}

1. Schramm LL. Surfactants: Fundamentals and Applications in the Petroleum Industry. Cambridge university press; 2010.

2. Kokal S, Al-Kaziz A. EOR Challenges and Opportunities. World Petroleum Council; 2010, 1-3.

3. Baviere M, Glenate P, Labrid J. Improved Oil Recovery by Use of Chemicals in Combination. Paper SPE 27821 presented at the 1994 SPE/DOE Symposium on Improved Oil Recovery; Apr 17-20; Tulsa, OK. 
4. Grigg RB, Bai B, Liu Y. Competitive adsorption of a hybrid surfactant system onto five minerals, Berea sandstone, and limestone. SPE Annual Technical Conference and Exhibition. Society of Petroleum Engineers; 2004; Houston, Texas.

5. Hirasaki GJ, Miller CA, Puerto M. Recent advances in surfactant EOR. SPE Annual Technical Conference and Exhibition. Society of Petroleum Engineers; 2008; Denver, Colorado, USA.

6. Paria S, Manohar C, Khilar KC. Adv Colloid Interface Sci. Elsevier; 2005. p. 75-95.

7. Khilar KC. Adsorption of anionic and non-ionic surfactants on a cellulosic surface. Colloids Surf A. 2005; 2522(3): 221-9.
8. Lv W, Bazin B, Ma D, Liu Q, Han D, Wu K. Static and dynamic adsorption of anionic and amphoteric surfactants with and without the presence of alkali. J Petrol Sci Eng. 2011; 772:209-18

9. Wang W, Gu Y. Interactions of Alkaline Solutions with Oil-Brine-Rock Systems in ASP Flood Processes. Paper 2003-142 presented at Petroleum Society's Canadian Petroleum Conference 2003; 2003 Jun 10-12; Calgary, Alberta.

10. Mustafa S, Dilara B, Nargis K, Naeem A, Shahida P. Surface properties of the mixed oxides of iron and silica. Colloids Surf A. 2002; 2053:273-82 